\title{
Letter to the Editors
}

\section{Impact of CYP3A5 genetic polymorphism on pharmacokinetics of tacrolimus in healthy Japanese subjects}

\author{
Yoshiharu Suzuki, ${ }^{1,2}$ Masato Homma, ${ }^{1,2}$ Kosuke Doki, $^{2}$ Fumio Itagaki $^{2}$ \& Yukinao Kohda ${ }^{1,2}$ \\ ${ }^{1}$ Department of Pharmaceutical Sciences, Graduate School of Comprehensive Human Sciences, University of Tsukuba and \\ ${ }^{2}$ Department of Pharmacy, Tsukuba University Hospital, Tsukuba, Ibaraki, Japan
}

Tacrolimus (TAC), a calcineurin inhibitor, is an important immunosuppressive agent for treating autoimmune disease, including myasthenia gravis and rheumatoid arthritis, as well as for preventing allograft rejection in organ transplantation [1]. Since the therapeutic range of blood TAC is narrow, current interest focused on this drug is to maintain optimal blood concentrations in therapeutic drug monitoring (TDM) based on pharmacogenomic data, such as CYP3A5 and MDR1 gene polymorphisms [2]. Fukudo et al. [2] have reported that both CYP3A5 genotype and MDR1 mRNA expression were important factors affecting TAC pharmacokinetics in paediatric living related liver transplantation. Choi et al. [3] have revealed the impact of CYP3A5 genotype on TAC pharmacokinetics in healthy Koreans, where the area under the concentrationtime curve (AUC) of TAC in subjects with $C Y P 3 A 5^{*} 3 /^{*} 3$ was 2.5-fold higher compared with CYP3A5* 1 carriers. We have examined the impact of CYP3A5 and MDR1 genetic polymorphism on TAC pharmacokinetics in healthy Japanese by using population pharmacokinetics (PPK) analysis. This study was approved by the Ethical Committee of University of Tsukuba (Tsukuba, Japan) and written informed consent was obtained in each case.

Twenty healthy subjects received a single dose of oral TAC (2 mg; Prograf; capsule Astellas Pharma Inc., Tokyo, Japan). Venous blood samples for determining blood TAC were collected before and 1,2, 4 and $8 \mathrm{~h}$ after the administration. Blood TAC was determined by microparticle enzyme immunoassay. Since the blood TAC concentration at $8 \mathrm{~h}$ after dose was as low as the detection limit for this method $\left(1.5 \mathrm{ng} \mathrm{ml}^{-1}\right)$, we did not measure the concentration after $8 \mathrm{~h}$.PPK analysis was performed using WinNonMix (Version 2.0; Pharsight, Mountain View, CA, USA) with a onecompartment model to calculate apparent clearance (CL/F) and volume of distribution (V/F). The absorption rate constant $\left(k_{a}\right)$ was fixed to a reported value $\left(4.5 \mathrm{~h}^{-1}\right)$ [4].Age, body weight, sex, and CYP3A5 and MDR1 genotypes were evaluated as the covariates by conducting a forward and back- ward stepwise regression analysis. Genome DNA was isolated from peripheral blood by using the QIAamp DNA Mini Kit (Qiagen $\mathrm{GmbH}$, Hilden, Germany). The genotyping of CYP3A5 and MDR1 at the position of $1236 \mathrm{C} \rightarrow \mathrm{T}$, $2677 \mathrm{G} \rightarrow \mathrm{A} / \mathrm{T}$ and $3435 \mathrm{C} \rightarrow \mathrm{T}$, was conducted by the polymerase chain reaction-restriction fragment length polymorphism (PCR-RFLP) method [5, 6]. MDR1-1517a T $\rightarrow C$ polymorphism, which was reported by Takane et al. [7] as the predictive factor of the expression level of MDR1 mRNA (NCBI dbSNP ID: rs28381796), was also genotyped by using a PCR-RFLP method developed in our laboratory.

TAC pharmacokinetic parameters are summarized in Table 1. The $\mathrm{AUC}_{0-8 \mathrm{~h}}$ in subjects with $C Y P 3 A 5^{*} 3 /{ }^{*} 3$ were 1.8 fold higher than that in $C Y P 3 A 5^{*} 1$ carriers $(P=0.03)$, which agreed with the report of Choi et al. [3]. MDR1-1517a T/C genotype $(n=4)$ tended to have lower $\mathrm{AUC}_{0-8 \mathrm{~h}}$ compared with $-1517 \mathrm{a}$ T/T genotype $(n=10) \quad(20.8 \pm 11.1$ vs. $29.2 \pm 8.2 \mathrm{ng} \mathrm{h} \mathrm{ml}^{-1}$ ) in CYP3A5* 1 carriers, although the difference was not statistically significant because of insufficient power.

We conducted PPK analysis to estimate the contribution of CYP3A5 genotype on individual variations of TAC pharmacokinetics. Among the covariates, body weight affected the $V / F$ and $C L / F$, and $C Y P 3 A 5^{*} 1$ allele only affected $C L / F$ (Table 2). The estimated $\mathrm{CL} / F$ in subjects with CYP3A5*1 carriers was 1.5 times higher than that in subjects with CYP3A5*3/*3 (Table 2), which was comparable to measured values. The interindividual variability in $\mathrm{CL} / F$ with final model 4 was reduced from that with model 3 including no genetic covariates ( $22.4 \%$ to $9.7 \%$, base model $1 ; 40.3 \%$ ). These results suggest that approximately $32 \%$ of the interindividual variation of TAC CL/F can be explained by CYP3A5 polymorphism in healthy Japanese. This value is greater than the $9 \%$ and $23 \%$ reported, which were obtained in paediatric [2] and adult [8] liver transplantation situations, respectively. The liver transplantation is very complex in estimating the efficacy of CYP3A5 polymorphism on TAC pharmacokinetics, because of several issues such as the 
Effect of CYP3A5 polymorphism on tacrolimus pharmacokinetics in healthy Japanese

\begin{tabular}{|c|c|c|c|c|c|}
\hline CYP3A5 & $n(\mathrm{M} / \mathrm{F})$ & $\begin{array}{l}\text { Age } \\
\text { (years) }\end{array}$ & $\begin{array}{l}\text { Weight } \\
\text { (kg) }\end{array}$ & $\begin{array}{l}\text { AUC }_{0-8 h} \\
\left(\mathrm{ng} \mathrm{h} \mathrm{m}^{-1}\right)\end{array}$ & $\begin{array}{l}\mathrm{CL} / \mathrm{F} \\
\left(\mathrm{l} \mathrm{h}-1 \mathrm{~kg}^{-1}\right)\end{array}$ \\
\hline *1 carrier & $14(13 / 1)$ & $35.6 \pm 8.0$ & $66.2 \pm 11.0$ & $\begin{array}{l}26.8 \pm 9.5 \\
(21.8,31.7)\end{array}$ & $\begin{array}{l}1.33 \pm 0.61 \\
(1.01,1.64)\end{array}$ \\
\hline$* 3 / * 3$ & $6(5 / 1)$ & $26.2 \pm 1.3$ & $66.2 \pm 11.8$ & $\begin{array}{l}48.0 \pm 21.9 \\
(30.5,65.6)\end{array}$ & $\begin{array}{l}0.73 \pm 0.25 \\
(0.53,0.93)\end{array}$ \\
\hline$P$-valuet & - & 0.009 & - & 0.032 & 0.032 \\
\hline
\end{tabular}

†Mann-Whitney U-test. Values are given as number of subjects or mean \pm SD. Values in parentheses represent the $95 \%$ confidence interval.

\section{Table 2}

Summary of analysis models estimating for pharmacokinetic parameters of tacrolimus

\begin{tabular}{|c|c|c|c|}
\hline \multirow[b]{2}{*}{ Models } & \multirow{3}{*}{$\begin{array}{c}\Delta \text { OFVt } \\
-\end{array}$} & \multicolumn{2}{|c|}{ Interindividual variability } \\
\hline & & VIF & $\mathrm{CL} / \mathrm{F}$ \\
\hline $1 \quad V / F=\theta_{1} \cdot \mathrm{e}^{\eta_{i}}, \mathrm{CL} / F=\theta_{2} \cdot \mathrm{e}^{\eta_{i}}$ & & $32.6 \%$ & $40.3 \%$ \\
\hline $2 V / F=\theta_{1} \cdot \mathrm{BW} \cdot \mathrm{e}^{\eta_{i}}, \mathrm{CL} / F=\theta_{2} \cdot \mathrm{e}^{\eta_{i}}$ & 8.46 & $21.0 \%$ & $36.1 \%$ \\
\hline $3 \quad \begin{array}{l}V / F=\theta_{1} \cdot \mathrm{BW} \cdot \mathrm{e}^{\eta_{i}} \\
\mathrm{CL} / F=\theta_{2} \cdot \mathrm{BW} \cdot \mathrm{e}^{\eta_{i}}\end{array}$ & 7.90 & $23.1 \%$ & $22.4 \%$ \\
\hline $\begin{array}{l}4 \quad V / F=\theta_{1} \cdot \mathrm{BW} \cdot \mathrm{e}^{\eta_{i r}} \\
\mathrm{CL} / F=\theta_{2} \cdot \mathrm{BW} \cdot \theta_{3}{ }^{C Y P 3 A 5^{*}} \cdot \mathrm{e}^{\eta_{i}}\end{array}$ & 7.48 & $26.7 \%$ & $9.7 \%$ \\
\hline
\end{tabular}

BW, body weight; CL/F, apparent clearance; OFV, objective function value; $\triangle O F V$, difference in OFV; VIF, apparent volume of distribution. Parameter of model 4 is described by the following equations: $V / F=3.24 \cdot B W, C L / F=$ $0.55 \cdot B W \cdot 1.49^{C Y P 3 A 5^{* 1}}$ (if the subject was a CYP3A5*1 allele carrier, then CYP3A5*1 $=1$, otherwise 0$).+\triangle \mathrm{OFV}$ greater than $3.84($ d.f. $=1)$ was accepted as statistically significant $(P<0.05)$.

mismatch in genotype between recipients and donors and change in enzyme activities due to liver function, which may explain the discrepancy between the present and reported values. Because these factors associated with liver transplantation do not affect TAC pharmacokinetics in patients with myasthenia gravis and rheumatoid arthritis as well as healthy subjects, it is considered that the impact of CYP3A5 genotype on TAC TDM for autoimmune diseases is important. We therefore suggest that it would be useful to include CYP3A5 genotyping in TAC therapy for autoimmune diseases, especially in the Asian population, which frequently carry the $C Y P 3 A 5^{*} 1$ allele.

\section{REFERENCES}

1 Kawai S, Yamamoto K. Safety of tacrolimus, an immunosuppressive agent, in the treatment of rheumatoid arthritis in elderly patients. Rheumatology 2006; 45: 441-4.

2 Fukudo M, Yano I, Masuda S, Goto M, Uesugi M, Katsura T, Ogura Y, Oike F, Takada Y, Egawa H, Uemoto S, Inui K. Population pharmacokinetic and pharmacogenomic analysis of tacrolimus in pediatric living-donor liver transplant recipients. Clin Pharmacol Ther 2006; 80: 331-45.
3 Choi JH, Lee YJ, Jang SB, Lee JE, Kim KH, Park K. Influence of the CYP3A5 and MDR1 genetic polymorphisms on the pharmacokinetics of tacrolimus in healthy Korean subjects. Br J Clin Pharmacol 2007; 64: 185-91.

4 Jusko WJ, Piekoszewski W, Klintmalm GB, Shaefer MS, Hebert MF, Piergies AA, Lee CC, Schechter P, Mekki QA. Pharmacokinetics of tacrolimus in liver transplant patients. Clin Pharmacol Ther 1995; 57: 281-90.

5 van Schaik $\mathrm{RH}$, van der Heiden IP, van den Anker JN, Lindemans J. CYP3A5 variant allele frequencies in Dutch Caucasians. Clin Chem 2002; 48: 1668-71.

6 Qian W, Homma M, Itagaki F, Tachikawa H, Kawanishi Y, Mizukami K, Asada T, Inomata S, Honda K, Ohkohchi N, Kohda Y. MDR1 gene polymorphism in Japanese patients with schizophrenia and mood disorders including depression. Biol Pharm Bull 2006; 29: 2446-50.

7 Takane H, Kobayashi D, Hirota T, Kigawa J, Terakawa N, Otsubo K, leiri I. Haplotype-oriented genetic analysis and functional assessment of promoter variants in the MDR1 (ABCB1) gene.J Pharmacol Exp Ther 2004; 311: 1179-87.

8 Li D, Lu W, Zhu JY, Gao J, Lou YQ, Zhang GL. Population pharmacokinetics of tacrolimus and CYP3A5, MDR1 and IL-10 polymorphisms in adult liver transplant patients. J Clin Pharm Ther 2007; 32: 505-15.

\section{RECEIVED}

7 January 2008

ACCEPTED

10 February 2008

\section{PUBLISHED OnlineEarly}

13 March 2008

\section{CORRESPONDENCE}

Masato Homma, PhD, Department of Pharmaceutical Sciences, Graduate School of Comprehensive Human Sciences, University of Tsukuba, Ten-nodai 1-1-1, Tsukuba, Ibaraki 305-8575, Japan. E-mail:masatoh@md.tsukuba.ac.jp

Response to 'Influence of the CYP3A5 and MDR1 genetic polymorphisms on the pharmacokinetics of tacrolimus in healthy Korean subjects'. (Br J Clin Pharmacol. 2007; 64: 185-91). 